\title{
Applications of Financial Shared Service Model in Chinese Corporations
}

\author{
Yihan Wang \\ School of Accounting \\ Nanjing University of Finance and Economics \\ Nanjing, China
}

\author{
Junjie Gao \\ School of Accounting \\ Nanjing University of Finance and Economics \\ Nanjing, China
}

\author{
Liya Ma \\ School of Accounting \\ Nanjing University of Finance and Economics \\ Nanjing, China
}

\begin{abstract}
With deep integration of Information Technology with other industries, finance and accounting are gradually moving towards digitalization. Financial Shared Service Center is also one of the products in the information age, promoting advance developments of accounting digitalization. This paper studies the applications of Financial Shared Service Center based on the perspective of accounting digitalization. It takes two Chinese listed corporations as examples, and compares their financial shared service models and organizational structures based on strategic accounting. The paper proposes relevant strategies for the construction of financial shared service centers, aiming to provide practical suggestions for other companies.
\end{abstract}

Keywords-financial shared service; accounting information technology; case study

\section{INTRODUCTION}

In the era of big data, accounting information technology has developed rapidly, and management accounting digitalization and financial shared services has become hot issues for study. In the context of global economic integration, with the expansion of the company's development area, accounting activities need to share and interconnect information. The Financial Shared Service Center (FSSC), supported by information technology, standardizes, streamlines, and informs accounting by centralizing financial information and centrally managing accounting personnel, allowing most of the company's costs to be invested in the enterprise budget management indicators and business performance evaluation, and effectively promote the development of management accounting information.

Management accounting is an effective analysis through the data of financial accounting, and plays an important role in the four important aspects of enterprise planning, decision-making, control and evaluation. Management accounting started early in the West, and has been widely used in enterprise management and public management. In
China, due to historical conditions and other factors, management accounting digitalization has not been developed and valued. Therefore, the Ministry of Finance in China has also carried out positive reforms in management accounting. On January 29, 2014, the Ministry of Finance issued the "Guiding Opinions of the Ministry of Finance on Promoting the Construction of a Management Accounting System", which reflects the determination of the Chinese government to comprehensively promote the reform of management accounting. The introduction also provides strong political support for promoting the development of management accounting digitalization based on the financial shared service model.

In the context of economic globalization, competition among enterprises has become increasingly fierce, and the work of management accounting has become more and more personalized and diversified, and corporate decision-makers have attached importance to the issue of taking advantage of the competition. In this demand market, promoting the development of the financial shared service model based on the management accounting information model can not only enhance the competitiveness of enterprises in the market. At the same time, the development of management accounting digitalization can also make the management accounting function develop better, analyze data information more efficiently, and provide powerful financial analysis and decision support for enterprises to promote better and faster progress.

In this paper, Suning Commerce Group Corporation and Zhongxing Telecommunication Equipment Corporation (ZTE), which are relatively successful in the construction of financial shared service center, are the case study objects. By comparing the financial shared service models of the two, this paper proposes the development strategy of improving the financial shared service mode from the perspective of management accounting digitalization. In order to provide practical advice for the development of management 
the same type of stores in the same city. According to the analysis of its annual report, the decline ratio was $26.32 \%$ and $34.38 \%$, respectively. In order to strengthen the financial control management of Suning's headquarters for its stores and to meet the management philosophy of "cross-regional integration", Suning's management proposed to establish a unified financial center and effectively provide back-office services. In terms of cost control and improvement of management methods, according to the annual report, in 2004 , the inventory increased by $137.51 \%$ compared with the beginning of the period. In 2005, the year-on-year growth of inventory was as high as $162 \%$, and the average inventory increased by $155 \%$ year-on-year. The year-on-year growth rate only reached $75.13 \%$, which is far less than the average inventory growth. It can be inferred that the company's inventory turnover rate will decrease, and the store operation cost will be increased and the operation efficiency will be reduced during the expansion of Suning. In this context, Suning upgraded SAP/ERP in 2006, and in order to control operating costs and improve efficiency, Suning initially established a financial management headquarters in the same year, and increased the need to establish a financial shared center.

\section{B. Organizational Structure}

The development of Suning Group FSSC has formed a relatively complete organizational structure, and established three secondary centers - the bill center, the account book center and a management department. The bill center includes bill scanning, bill collation, bill products, bill binding and bill custody. The accounting book center consists of account inspection, account reconciliation, accounting treatment, report products and management recommendation. The management department is mainly human resource management and operation management.

\section{Information Systems}

Suning Co. establishes a whole supply chain idea. The whole supply chain refers to end-to-end, from the beginning to the end of customers, not only with suppliers, but also with enterprises and downstream consumers. In order to ensure the orderly implementation of the whole supply chain idea, the application of information system is very important. From the perspective of management accounting information, Suning business financial center system mainly uses enterprise resource planning system (SAP), network reimbursement system (SOA), bill imaging system (DCM IOP), fund management system (FMS), file management system, asset management system, etc.

1) Enterprise resource planning system (SAP): SAP system mainly carries out standardized operation of logistics management, financial management, human resources and information data management of Suning Co., highly integrated, and realizes the integration of information operation of business chain. In the development process of suning, the early ERP system knowledge is a simple purchase-sell-stock system, which is more and more difficult to carry the huge business flow of Suning, and the 
3) Fund management system (FMS): The FMS system mainly establishes six major platforms, namely, business processing platform, fund settlement platform, investment platform, interface platform, basic management platform, and direct banking platform. Through the FMS system, Suning Corporation handled the payment and payment business of the company's external system after opening the bank's direct business with the bank, and carried out centralized management of funds to realize real-time monitoring of funds.

4) Bill imaging system (DCM IOP):The bill image system mainly uses the information technology to scan and archive the original documents. The system can upload the original documents to the corresponding business system for processing in the business-generating area, realizing paperless and informationized, and at the same time, without time limit and Space restrictions. Moreover, the preservation of the bill image reduces the risk and improves the convenience of querying the bill. This system uses virtual printing technology and OCR technology to achieve functions such as managing electronic voucher and bills.

Financial shared information system is not only the above four types, but also includes consolidated statement system, employee reconciliation management system, accounts receivable verification system, etc. Each system relys on information technology to supplement each other, and ensures the standardization and informatization of the business process of financial shared service center.

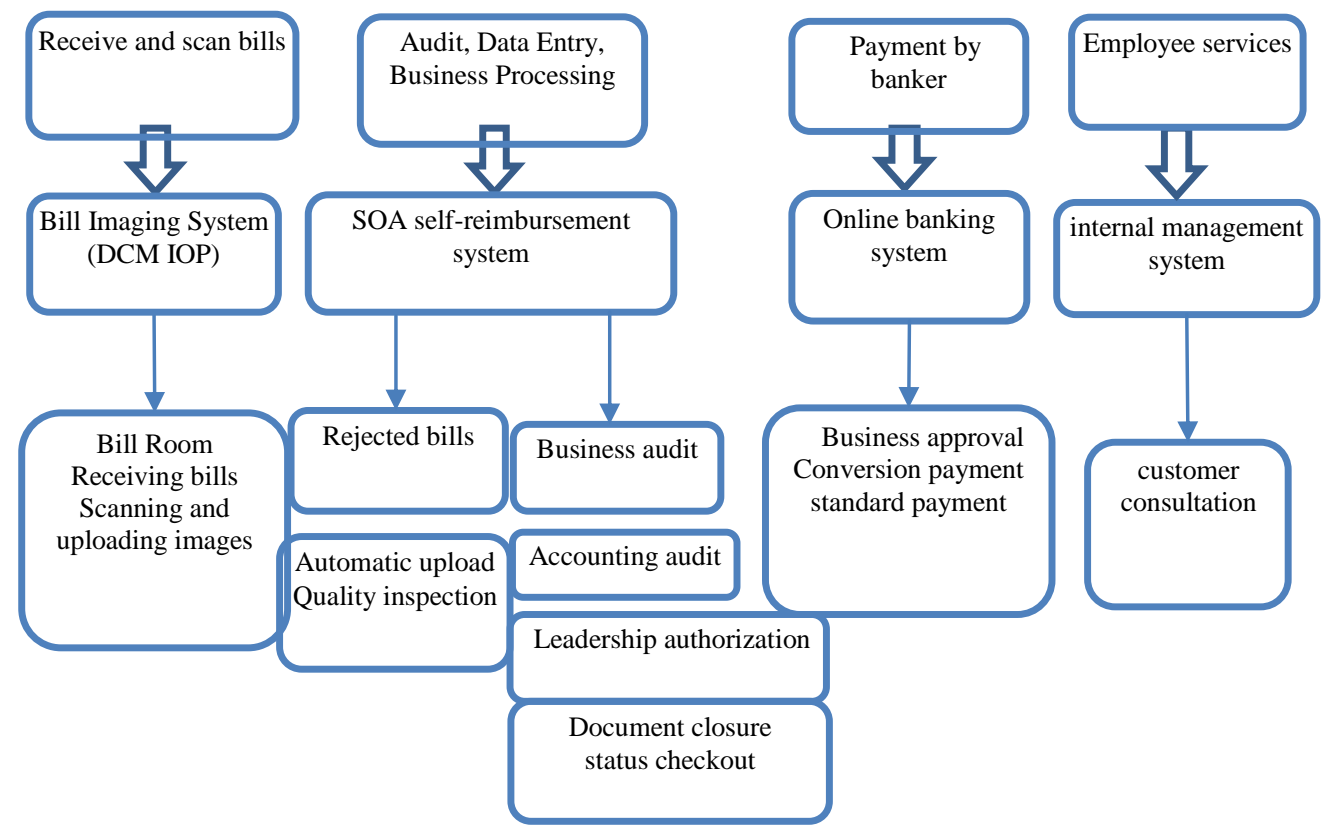

Fig. 1. Suning FSSC expense reimbursement business process.

\section{Business Process}

Suning financial shared center has the characteristics of standardization and high efficiency for the company's financial process, and can standardize repetitive work. By establishing and utilizing SAP system, bill imaging system and other information systems, the group processes the following business processes: expense reimbursement process, accounts receivable (payable) process, fixed assets process and general ledger process.

- Expense reimbursement process is mainly divided into: bill scanning, bill review, data entry, account 
processing, bank payment and employee service. This process mainly adopts the SOA self-help reimbursement system, in the use of the information system, broke the employees in reimbursement of space limitations, at the same time, SOA self-help reimbursement system is not only play a role in the cross-regional function, through the Internet, the improvement of information technology, convenient the documents transfer process, improve the efficiency of the reimbursement. The main operating procedures and application system of expense reimbursement process are shown in "Fig. 1".

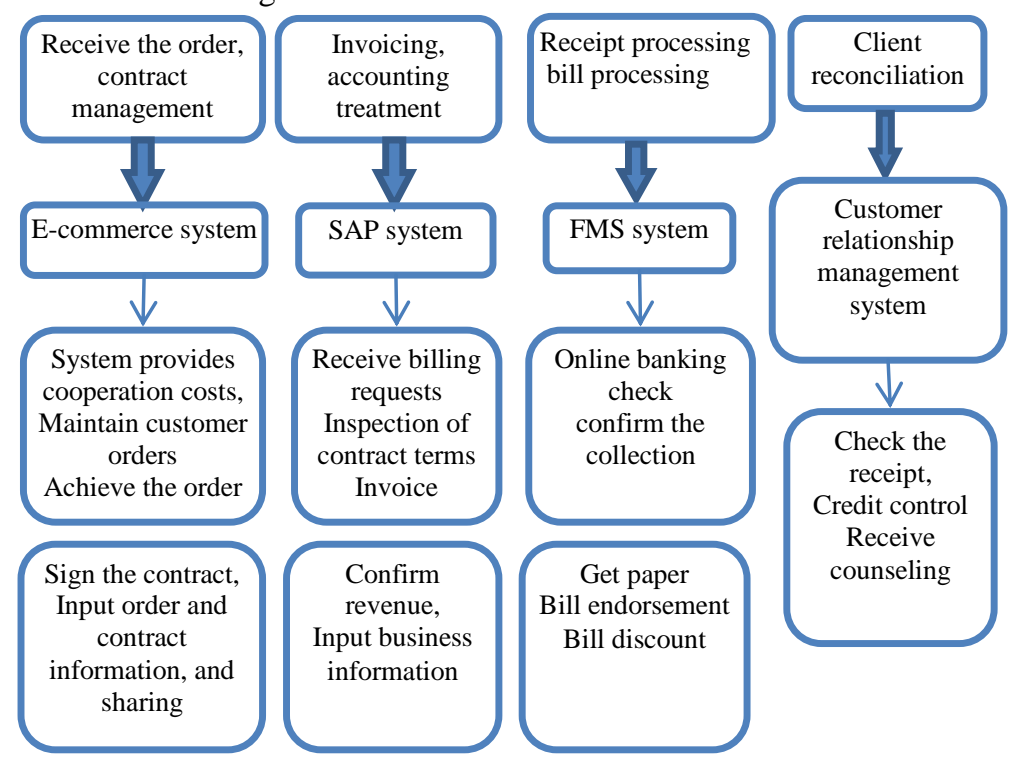

Fig. 2. Suning FSSC accounts receivable business process.

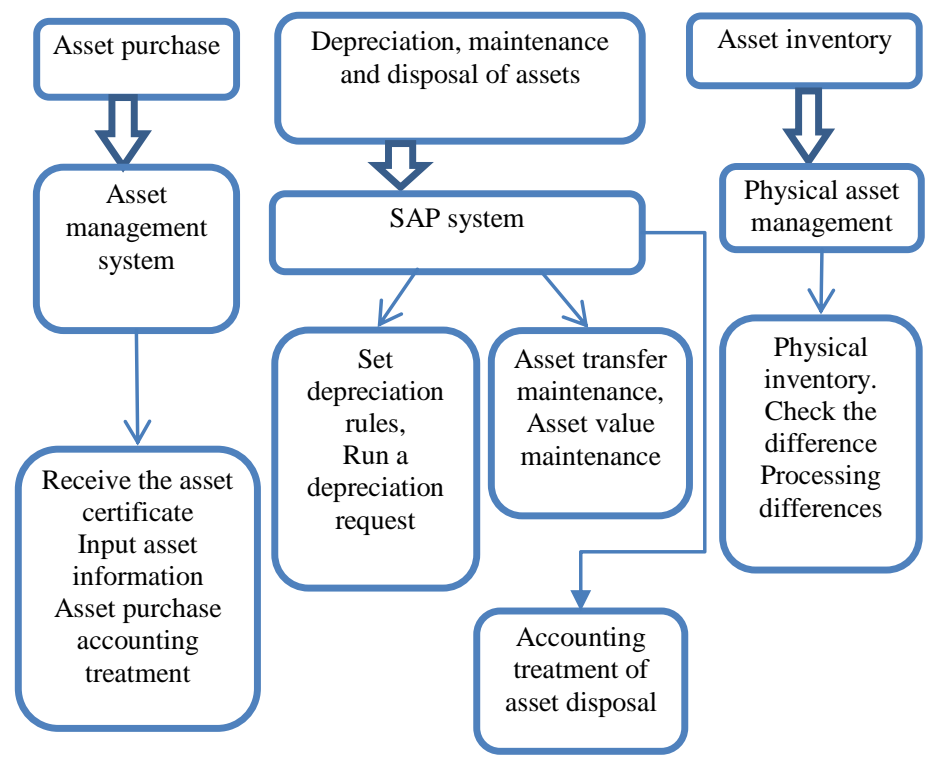

Fig. 3. Suning FSSC fixed assets business process.

- The process of fixed assets mainly deals with the changes of assets and other businesses, including asset purchase, depreciation, maintenance, inventory and other business operations. The main operating
- Accounts receivable process mainly occurs between Suning corporation and its customers, which is a basic business process to be processed by the financial shared center. This process mainly includes: order confirmation and contract management, collection and account processing, bill management, customer reconciliation and other processes. "Fig. 2" lists the main operating procedures and application system of accounts receivable process. 
human resources and operations. The functions of these four departments are clearly divided and they manage the business of financial shared center in parallel.

In ZTE, its organizational structure is unique and is mainly divided into three centers: financial shared center, strategic financial management, financial and business management. The financial shared center offers standardized as well as informational financial services. The strategic financial management and financial and business management analyze the financial information, and they also participate in company management decisions, better coordinated development, and play the function of management information. The division of functions of this organizational structure is clearer, and the use of financial information data is more thorough. Compared with Suning's organizational structure, ZTE has strengthened its management development of business and corporate strategic development on the basis of high-quality financial accounting functions. Also, to some extent, ZTE strengthens management accounting functions, and constructs the integration of financial management.

\section{B. Information Systems}

The financial information system adopted by Suning corporation, including SAP System, Bill Imaging System and Fund Management System, is briefly introduced in the paper. In addition to the SAP system used by Suning, ZTE has basically applied other information systems in its financial shared services. However, in terms of the framework of information system, ZTE established an integrated financial system network. Through optimization and reconstruction of the previous financial processing process, it finally established an integrated system of six subsystems, including the system based on the basic business operation process and the control system based on the operation process. The framework of ZTE integrated network financial system is shown in "Fig. 4".

As previously stated, the organizational structure of Suning financial shared center is mainly composed of three secondary centers and one management department: bill center, statement center, accounting center, and the management department directly under the management of

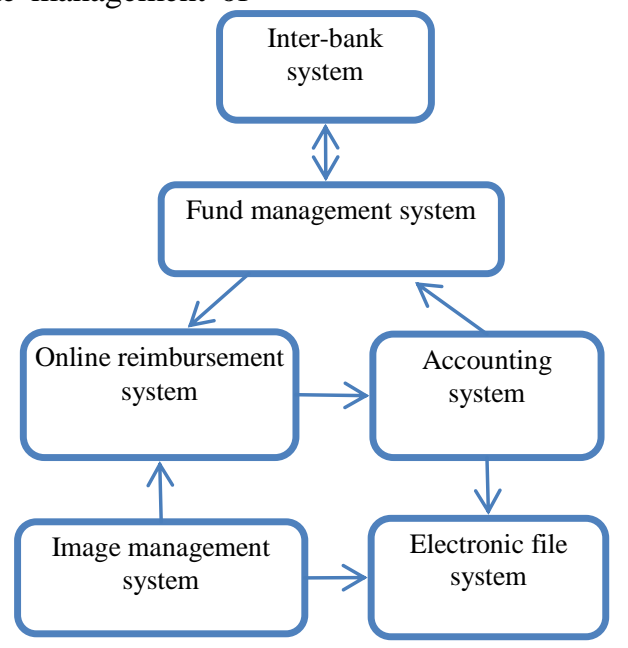

Fig. 4. ZTE FSSC integrated network financial system. 
of financial management mode at the same time, make the

\section{Performance Evaluation System}

To maximize the function of management accounting, scientific evaluation is indispensable. Fair appraisal system for employees is beneficial to stimulate their working motivation to the greatest extent. In the process of the development of financial shared center, ZTE has established a distinctive performance appraisal system. It is based on the balanced score method and joined the piecework wage system to strengthen the supervision of service quality, establish a perfect appraisal system and provide a measurement system for the standardized operation of financial shared service model.

\section{StRATEgIES OF FinANCIAL SHAREd SERVICE CENTER CONSTRUCTION}

\section{A. Perfecting the Framework of Information System and Strengthening the Ability of Information Integration}

The development of management accounting information needs the support of financial information system. In the comparison between Suning and ZTE's financial shared mode, we find that the successful factors of the development of ZTE's shared service mode include the establishment of integrated information system network, which can share information and data efficiently and scientifically in the perfect system through the mutual operation and coordination between each system network and its subsystems. System should be established in order to clarify the relationship between data in the system operation and the transmission process, and to coordinate the operation of the financial system and business system, which are operated independently in original, and avoid the separation of financial information and business information, so as to integrate information data fast, stabilize the operation of system and speed up the informatization of the management accounting development.

\section{B. Utilizing the Cloud Computing Technology to Strengthen Mobile Office}

Taking Suning corporation as an example, the application of information system accelerates the recording and operation of financial data, and to a certain extent saves employees' time and operating costs. However, Suning's process operation and information system efficiency are still insufficient. The operation of large-scale information system needs to be cooperated with large-scale clients, but the virtual clients are not popular. In the analysis of the development of financial shared model of ZTE, we find that it is now in the fourth stage of financial cloud, and its cloud service can meet the financial needs of companies around the world in the first time and provide efficient services. In order to develop the digitalization of management accounting, the use of cloud computing can further reduce the cost of physical facilities, and reduce the entity client configuration. With the help of a cloud computing platform to establish financial Shared services center can also meet ZTE's need to establish a similar "accounting shared service, business support and strategic decision support" tripartite coordination enterprise internal financial and business highly collaborative. Meanwhile, the storage and transmission of cloud data can also support mobile office, and the business data can be transferred to the financial center in the first time to ensure the timeliness of information and data.

\section{Strengthening Process Optimization and Building Big Data Analysis Model}

The enhancement of process optimization ensures that the information system keeps pace with times and reduces the deficiency and resource consumption in the process through the real-time monitoring and optimization of business operations. In Suning financial shared service model, it can be found that there is a certain separation between process operation and business level, and process optimization needs to be strengthened. In this paper, DMAIC model from 6 sigma can be used to enhance the optimization of the process. DMAIC model operation mainly includes the following processes: Definition, Measurement, Analysis, Improvement and Control. In the process optimization, we can apply the principles and techniques of statistics, and find the process problems fundamentally and complete the process reengineering to some extent. In addition, the financial sharing organizational structure of Suning corporation mainly includes bill center, account table center, accounting center and the management department directly under the management of human resources and operations. The single financial data processing business of Suning corporation may be divorced from the business essence and lacks support for the management data. Therefore the group can build a data center, using big data analysis model, to deal with all the financial data and information from the other three centers, such as analyzing the decrease in customer credit to reduce the operation risk, and effective statistics can be made on the customer's business behavior in the receivables and payables process. Also, Based on the analysis of the customer's financial data, we can judge their ability to fulfill the agreement .The establishment of the data center will manage and apply the financial information, strengthen the play of management and accounting functions by means of information technology, and strengthen the ability to the business and the ability to forecast the future operation.

\section{Improving the Employee Performance Appraisal System and the Knowledge Management System}

With the standardized application of the information system, the completion of the business volume of the company's department and individual business can be supervised and managed in the first time. A suitable performance appraisal system is not only conducive to motivating the grassroots team of the company, but also can enhance the management's ability to control employees. Since Suning Financial Shared Center is not only the internal financial center of the company, but also the commercialized and corporatized financial shared service center, the establishment of the assessment system needs to be carried out from both the organization and the staff. The organization evaluation needs to consider its operating costs, 
labor costs, etc. And also, Suning corporation financial shared services center is a commercial business company, and it provides financial shared services for other enterprises. In terms of organization assessment, it can focus on its profit and the business value of management mode, meeting the growth target of the company interests, and it can build a multidimensional system of management accounting, at least in the two dimensions of turnover and profitability, conducts assessment reports. It can manage the company according to the transfer price of the services, and use the supply of shared services for customers as the key indicator for assessment. The establishment of financial Shared service mode pursues the advantages of stability and low labor cost, and the establishment of perfect performance appraisal is conducive to strengthening organizational stability. For personal assessment, it is necessary to use the information system data to evaluate his/her work efficiency and development ability. After referring to the development of financial shared center of ZTE, it is advisable to establish a combination of balanced scorecard and ERP information system to form a more effective management assessment platform. On the other hand, improving the knowledge management system, allowing employees to improve professional skills and workplace ability, and ensuring the career development of employees, can effectively improve the degree of staff enthusiasm and lay a foundation for training management talents for the enterprise.

\section{CONCLUSION}

Nowadays, financial shared service mode is in the rapid application and development stage in Chinese enterprises. In the financial shared center, the application of information system accelerates the development of management accounting informatization. This paper mainly analyzes the construction and development strategy of financial shared mode from the perspective of management accounting, so as to improve the operation of financial shared mode and achieve the purpose of developing management accounting digitalization.

\section{REFERENCES}

[1] D. Ulrich, "Shared Services: From Vogue to Value", Human Resource Planning, vol. 18, pp. 12-23, 1995.

[2] A.T. Rothwell, I. P. Herbert, W. Seal, "Shared service centers and professional employability". Journal of Vocational Behavior, vol.79, pp.241-252, 2011.

[3] R. Zhang, Y. Zhang, and Y. Huang. "Key Changes of Design on Financial Shared Service: Lessons of Chinese Group Companies." Iita International Conference on Services Science 2009. 